\title{
Descriptive epidemiology of deceased cases of COVID-19 reported during the initial wave of the epidemic in Canada, January 15 to July 9, 2020
}

\author{
Public Health Agency of Canada COVID-19 Surveillance and Epidemiology Team ${ }^{1}$
}

\begin{abstract}
This rapid communication describes deaths among cases of coronavirus disease 2019 (COVID-19) in Canada by province and territory and by case characteristics. Of the 106,804 cases of COVID-19 reported in Canada as of July 9, 2020, 8,749 resulted in death, which represents a mortality rate of 23.3 per 100,000 population, and a case fatality rate (CFR) of $8.2 \%$. Within Canada, the CFR ranged from $0 \%$ to $10.0 \%$ by province and territory, with the differences likely reflecting differences in the extent of the epidemic within each jurisdiction, and where and among whom localized outbreaks occurred (e.g. outbreaks in long term care homes, affecting older individuals with multi-morbidities). The CFRs increased with age and with the number of pre-existing medical conditions, and among residents of long term care and seniors' homes. Plans are underway to collect more detailed information on cases, including race and ethnicity, which will add to our understanding of the communities most impacted by COVID-19. Studies of excess mortality, a measure of the number of people who died from any cause as compared with the historical average, will help to clarify the full impact of COVID-19 within Canadian jurisdictions.
\end{abstract}

This work is licensed under a Creative Commons Attribution 4.0 Internationa License.

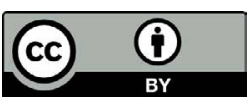

Affiliation

1 Public Health Agency of Canada, Ottawa, ON

Correspondence:

lindsay.whitmore@canada.ca

Suggested citation: Public Health Agency of Canada COVID-19 Surveillance and Epidemiology Team.

Descriptive epidemiology of deceased cases of COVID-19 reported during the initial wave of the epidemic in

Canada, January 15 to July 9, 2020. Can Commun Dis Rep 2020;46(10):344-8.

https://doi.org/10.14745/ccdr.v46i10a06

Keywords: COVID-19, Canada, mortality, epidemiology, case fatality rate

\section{Introduction}

By early July 2020, Canada had successfully flattened the initial wave of the coronavirus disease 2019 (COVID-19) pandemic, bringing the average number of reported daily cases down from a peak of 1,600 in the last week of April to 290 cases in the week leading up to July 9, 2020. Tragically, during this initial wave, Canada reported the $20^{\text {th }}$ highest crude mortality rate in the world as of July 9, 2020 (1). This rapid communication describes deaths among COVID-19 cases, using available data reported during this initial wave from January 1, 2020 to July 9, 2020, to inform action to minimise deaths due to COVID-19 moving forward.

\section{Current situation}

As of July 9, 2020, 106,804 cases of COVID-19 have been reported in Canada, and the number of reported deaths among these cases was 8,749 . The number of deaths reported daily increased steadily from the end of March to a peak in early May; an average of 177 deaths was reported daily between April
30 and May 6. The daily number of reported deaths steadily declined thereafter and in the week leading up to July 9, 2020, an average of 15 deaths was reported daily (Figure 1). This parallels the trend in the number of cases reported daily that was observed two to three weeks earlier. This was expected, since COVID-19-related deaths represent infections that occurred several weeks prior (2-4).

Canada's crude mortality rate as of July 9, 2020 was 23.3 COVID-19-related deaths per 100,000 population. Due to the time between the date of infection and the date of death, the final clinical outcome for more recently reported cases is not yet known and, therefore, this mortality rate likely underestimated the true rate. Canada's COVID-19 mortality rate was the $20^{\text {th }}$ highest worldwide, based on available data, though it was comparable or lower than several European and North American countries (1). It is important to note, however, that the number of COVID-19-related deaths within a country is based on several interrelated factors, including the capacity of the healthcare system, how deaths are defined and captured, the stage of the 
Figure 1: Daily reported deaths among cases of COVID-19 in Canada and seven day moving-average, March 8 to July 9, $2020(\mathrm{~N}=8,749)^{\text {a }}$

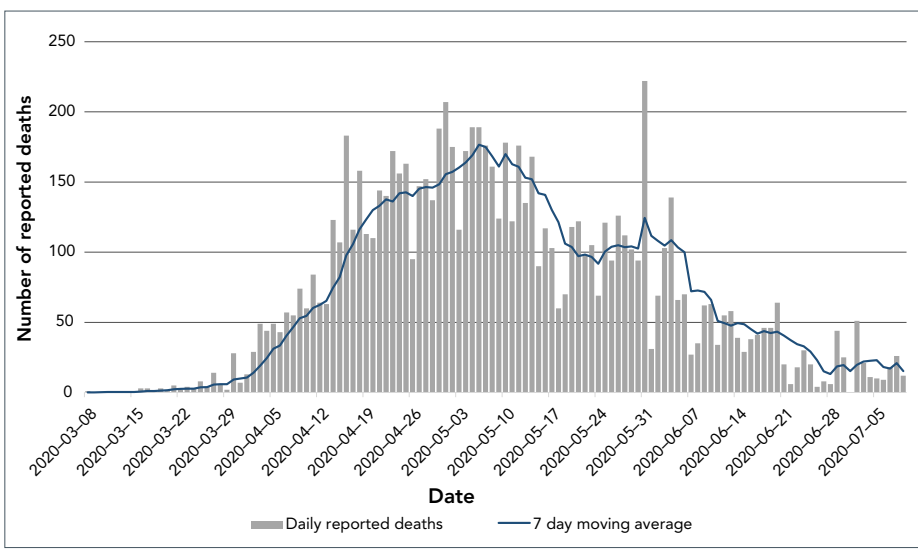

Abbreviation: COVID-19, coronavirus disease 2019

a The large increase on May 31, 2020 is a reporting artifact, and was due to Québec reporting deaths that were previously identified but unreported

epidemic and the health and age distribution of a country's population. For these reasons, comparisons across countries should be interpreted with caution.

As of July 9, 2020, Canada's case fatality rate (CFR), calculated by dividing the number of total deaths by the number of reported cases, was $8.2 \%$. As with the crude mortality rate, this is likely a biased measure of the true CFR, since the outcome (i.e. recovered or deceased) is not yet known for recently reported cases.

Across Canada, CFR ranged from $0 \%$ to $10.0 \%$ by province/territory (Table 1), and the mortality rate per 100,000 Canadian population ranged from 0.3 to 66.1 (among provinces and territories where there were deaths). After age standardizing, which adjusted for differences in the age distribution across provinces, the mortality rate per 100,000 population ranged from 0.2 to 60.4 . After age-standardization, differences in mortality rates by province were likely due to a number of factors, including, most prominently, the spread of COVID-19 within long term care and seniors' homes. Ontario and Québec had the highest age-standardized mortality rates at 18.4 and 60.4, respectively, with over $70 \%$ of these deaths occurring in long term care homes and seniors' residences (Table 1).

Indeed, the impact of the COVID-19 pandemic on residents of long term care and seniors' homes has been severe.

Approximately $81 \%$ of Canada's COVID-19 deaths have occurred among residents, as of July 9, 2020 (Table 1), with Ontario and Québec particularly affected, with 2,011 and 4,765 deaths, respectively, among residents of long term care and seniors'

Table 1: Deaths among COVID-19 cases in Canada as of July 9, 2020, by province and territory

\begin{tabular}{|c|c|c|c|c|c|c|}
\hline Province/territory & Total cases & Deaths ${ }^{a}$ & $\begin{array}{l}\text { Deaths among } \\
\text { residents of } \\
\text { long term care } \\
\text { and seniors' } \\
\text { homes }^{b}\end{array}$ & $\begin{array}{c}\text { Case fatality } \\
\text { rate }\end{array}$ & $\begin{array}{c}\text { Deaths per } \\
100,000 \\
\text { population }^{\mathrm{c}, \mathrm{d}}\end{array}$ & $\begin{array}{c}\text { Age } \\
\text { standardized } \\
\text { death rate per } \\
100,000^{c, e, f}\end{array}$ \\
\hline Québec & 56,216 & 5,609 & 4,765 & $10.0 \%$ & 66.1 & 60.4 \\
\hline Ontario & 36,348 & 2,703 & 2,011 & $7.4 \%$ & 18.6 & 18.4 \\
\hline Alberta & 8,519 & 161 & 117 & $1.9 \%$ & 3.7 & 4.8 \\
\hline British Columbia & 3,028 & 186 & 131 & $6.1 \%$ & 3.7 & 3.5 \\
\hline Nova Scotia & 1,066 & 63 & 57 & $5.9 \%$ & 6.5 & 5.8 \\
\hline Saskatchewan & 813 & 15 & 2 & $1.8 \%$ & 1.3 & 1.3 \\
\hline Manitoba & 325 & 7 & 1 & $2.2 \%$ & 0.5 & 0.6 \\
\hline Newfoundland and Labrador & 261 & 3 & 0 & $1.2 \%$ & 0.6 & 0.5 \\
\hline New Brunswick & 166 & 2 & 2 & $1.2 \%$ & 0.3 & 0.2 \\
\hline Prince Edward Island & 33 & 0 & 0 & $0 \%$ & $\mathrm{NDC}^{\mathrm{g}}$ & $\mathrm{NDC}^{\mathrm{g}}$ \\
\hline Yukon & 11 & 0 & 0 & $0 \%$ & NDCg & NDCg \\
\hline Northwest Territories & 5 & 0 & 0 & $0 \%$ & $\mathrm{NDC}^{g}$ & NDCg \\
\hline Nunavut & 0 & 0 & 0 & $0 \%$ & $\mathrm{NDC}^{9}$ & NDCg \\
\hline Canadah $^{h}$ & 106,804 & 8,749 & 7,086 & $8.2 \%$ & 23.3 & $23.3^{i}$ \\
\hline
\end{tabular}

Abbreviations: COVID-19, coronavirus disease 2019; NDC, no deaths calculated

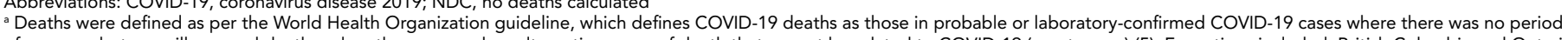

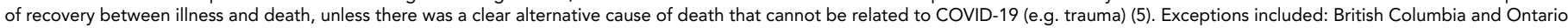

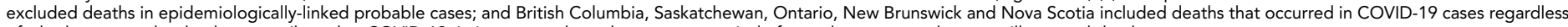
of whether or not the death was attributed to COVID-19, in instances where there was no period of complete recovery between illness and death

${ }^{b}$ Based on provincial and territorial websites, press briefings, web scanning, as of July 9, 2020

c Deaths per 100,000 population were not calculated for provinces and territories where there were no deaths

d Statistics Canada July 1, 2019 population estimates

e Direct age standardization using July 1, 2019 population estimates

${ }^{f}$ Age standardized death rate per 100,000 was determined using the detailed case information received by the Public Health Agency of Canada for 106,198 cases and 8,711 deaths

9 Deaths per 100,000 and age standardized death rate per 100,000 were not calculated in jurisdictions where there were no deaths

h The total for Canada includes 13 cases identified in repatriated travellers who were under quarantine in March 2020. Update on their status was unavailable

The age standardized death rate per 100,000 were standardized to the national Canadian population

Page $345 \quad$ CCDR • October 1, $2020 \bullet$ Vol. 46 No. 10 
homes. This may have been due to the population size, density and the extent of community transmission within these particular provinces (6).

Of the 106,804 cases and 8,749 deaths reported in Canada on July 9, 2020, more detailed information was reported to the Public Health Agency of Canada for 106,321 (99.5\%) cases and 8,711 (99.6\%) deaths by that same date. An analysis of COVID-19 related deaths by age, gender, pre-existing medical conditions and long term care and seniors' home resident status was conducted using this more detailed dataset provided by provinces and territories.

CFR was less than $1 \%$ in all age groups up until the age of 50 years, and then increased rapidly with age, with a CFR of $1.2 \%$ for those aged 50 to 59 years, increasing up to $34.4 \%$ for those aged 80 years and over (Table 2). Canadian females overall were more impacted, with a higher rate of deaths per 100,000 (24.9

Table 2: Case fatality rates and deaths per 100,000 population by age and gender, as of July 9, 2020 $(\mathrm{N}=106,321)$

\begin{tabular}{|l|r|r|r|r|}
\multicolumn{1}{|c|}{$\begin{array}{c}\text { Case } \\
\text { characteristics }\end{array}$} & Cases & Deaths & $\begin{array}{c}\text { Case } \\
\text { fatality } \\
\text { rate }\end{array}$ & $\begin{array}{c}\text { Deaths per } \\
100,000 \\
\text { population }\end{array}$ \\
\hline Age group & \\
\hline $0-19$ years & 7,791 & 1 & $0.01 \%$ & 0.01 \\
\hline $20-29$ years & 14,813 & 8 & $0.05 \%$ & 0.2 \\
\hline $30-39$ years & 14,854 & 15 & $0.1 \%$ & 0.3 \\
\hline $40-49$ years & 16,175 & 45 & $0.3 \%$ & 0.9 \\
\hline $50-59$ years & 16,140 & 200 & $1.2 \%$ & 3.8 \\
\hline $60-69$ years & 10,427 & 615 & $5.9 \%$ & 13.3 \\
\hline $70-79$ years & 7,832 & 1,570 & $20.1 \%$ & 54.7 \\
\hline 80 and older & 18,166 & 6,257 & $34.4 \%$ & 385.1 \\
\hline Total & 106,198 & 8,711 & $8.2 \%$ & 23.0 \\
\hline
\end{tabular}

Age group by gender ${ }^{b, c}$

Female

\begin{tabular}{|l|r|r|r|r|}
\hline $0-39$ years & 19,814 & 8 & $0.04 \%$ & 0.1 \\
\hline $40-59$ years & 17,827 & 94 & $0.5 \%$ & 1.9 \\
\hline $60-79$ years & 9,095 & 885 & $9.7 \%$ & 22.9 \\
\hline 80 and older & 12,457 & 3,713 & $29.8 \%$ & 381.8 \\
\hline Total & 59,193 & 4,700 & $7.9 \%$ & 24.9 \\
\hline
\end{tabular}

\section{Male}

\begin{tabular}{|l|r|r|r|r|}
\hline $0-39$ years & 17,519 & 16 & $0.1 \%$ & 0.2 \\
\hline $40-59$ years & 14,412 & 151 & $1.1 \%$ & 3.0 \\
\hline $60-79$ years & 9,117 & 1,294 & $14.2 \%$ & 35.8 \\
\hline 80 and older & 5,596 & 2,509 & $44.8 \%$ & 384.6 \\
\hline Total & 46,644 & 3,970 & $8.5 \%$ & 21.3 \\
\hline
\end{tabular}

Statistics Canada July 1, 2019 population estimates

Information was not available for $0.12 \%(n=123)$ of cases on age and $0.35 \%(n=371)$ of cases on gender

c Provinces and territories may define gender differently and some may be referring to biological sex among females compared with 21.3 among males). However, among cases, males had a higher CFR than females (8.5\% compared with $7.9 \%$ ). These latter findings echo a gender difference observed among cases of severe illness due to COVID-19 in other countries $(7,8)$, which may reflect gender differences in the prevalence of pre-existing medical conditions and in risk behaviours such as smoking (8).

Based on the limited information available on pre-existing medical conditions $(n=6,350)$, CFR generally increased as the number of pre-existing medical conditions increased, overall and across all age groups (Table 3 ). This increase was marked among those aged 60 to 79 years, where the CFR was $3.1 \%$ among those without a pre-existing medical condition and $25.5 \%$ among those with three or more pre-existing medical conditions.

Pre-existing medical conditions assessed in case reports provided to the Public Health Agency of Canada included cardiac disease, chronic neurological or neuromuscular disorder, diabetes, immunodeficiency disease/condition, liver disease, malignancy, renal disease and respiratory disease. Being a resident of a long term care or seniors' home also resulted in a higher CFR overall $(26.8 \%)$ and within each of the age groups. While the information on whether or not the case was a resident of a long term care or seniors' home was limited $(n=10,150)$, these findings were similar to those of other Canadian studies, in which the overall CFR among residents was estimated to be $36 \%(6)$, and was greater than that of older Canadians who were not living in such a setting (Personal communication, D. Fisman et al.). The higher CFR among this population likely reflects a degree of frailty and multi-morbidity among residents that increases the risk of severe outcomes, including death (9).

\section{Table 3: Age-specific case fatality rates among COVID-19 cases by pre-existing medical conditions and by long term care or seniors' home resident status, July $92020^{a}$}

\begin{tabular}{|c|c|c|c|c|c|c|c|c|}
\hline \multirow{4}{*}{$\begin{array}{c}\text { Case } \\
\text { characteristics }\end{array}$} & \multicolumn{8}{|c|}{ Deaths/cases (case fatality rate) } \\
\hline & \multicolumn{8}{|c|}{ Age (years) } \\
\hline & \multicolumn{2}{|c|}{$0-59$} & \multicolumn{2}{|c|}{$60-79$} & \multicolumn{2}{|c|}{80 and older } & \multicolumn{2}{|c|}{ Total cases } \\
\hline & $n / N$ & $\%$ & $n / N$ & $\%$ & $\mathrm{n} / \mathrm{N}$ & $\%$ & $n / N$ & $\%$ \\
\hline \multicolumn{9}{|c|}{ Number of pre-existing medical conditions $\mathrm{s}^{\mathrm{a}, \mathrm{b}}$} \\
\hline 0 & $4 / 4,150$ & $0.1 \%$ & $32 / 1,028$ & $3.1 \%$ & $67 / 224$ & $29.9 \%$ & $103 / 5,402$ & $1.9 \%$ \\
\hline 1 & $2 / 135$ & $1.5 \%$ & 6/157 & $3.8 \%$ & $12 / 55$ & $21.8 \%$ & $20 / 347$ & $5.8 \%$ \\
\hline 2 & $0 / 66$ & $0.0 \%$ & 18/141 & $12.8 \%$ & $39 / 129$ & $30.2 \%$ & $57 / 336$ & $17.0 \%$ \\
\hline 3 and more & $1 / 39$ & $2.6 \%$ & $26 / 102$ & $25.5 \%$ & $47 / 124$ & $37.9 \%$ & $74 / 265$ & $27.9 \%$ \\
\hline \multicolumn{9}{|c|}{ Long term care or seniors' home resident ${ }^{c}$} \\
\hline No & $6 / 8,122$ & $0.1 \%$ & $34 / 1,098$ & $3.1 \%$ & $35 / 171$ & $20.5 \%$ & $75 / 9,391$ & $0.8 \%$ \\
\hline Yes & $3 / 33$ & $9.1 \%$ & $45 / 213$ & $21.1 \%$ & $155 / 512$ & $30.3 \%$ & $203 / 758$ & $26.8 \%$ \\
\hline
\end{tabular}

Abbreviation: COVID-19, coronavirus disease 2019

a Information on pre-existing medical conditions was not available for $94.03 \%(n=99,971)$ of cases ${ }^{b}$ Pre-existing medical conditions were defined as: cardiac disease, chronic neurological or neuromuscular disorder, diabetes, immunodeficiency disease/condition, liver disease, malignancy, renal disease, and respiratory disease

' Information on whether or not the case was a resident of a long term care or seniors' home was not available for $90.45 \%(n=96,171)$ of cases 
There is increasing evidence that, similar to findings from the United States and the United Kingdom (10), individuals from racial and ethnic minorities within Canada are at increased risk for acquiring COVID-19 and for severe outcomes, including death $(11,12)$. Nationally, plans are underway to begin the collection of more detailed case information in the fall 2020, including race, ethnicity and socio-economic status.

\section{Conclusion}

Public health authorities across the country will continue to monitor closely the number of deaths among COVID-19 cases to inform additional measures to prevent fatal outcomes. Although deaths provide a late indication of COVID-19 transmission, they provide a clear indication of the severity and impact of the disease and highlight the need to protect vulnerable populations, including those who are older and living with multiple pre-existing medical conditions. Most especially, Canadians living in long term care and seniors' homes have been severely impacted, with higher case fatality rates compared with older Canadians who are not living in such settings. Accordingly, federal, provincial and territorial jurisdictions have implemented multiple measures to prevent transmission within such settings. These measures include updated guidelines on infection prevention and control, and specifically regarding care of residents in long term care homes (13), policy measures to ensure adequate staffing and to limit the movement of healthcare workers between facilities.

The infection fatality rate and excess mortality are other measures of mortality than can be used to describe the impact of COVID-19 in Canada. The infection fatality rate is defined as the number of deaths divided by the number of individuals infected. Unlike CFR, the infection fatality rate is not influenced by factors such as changes in laboratory testing strategies. Plans are currently underway to conduct rapid pan-Canadian and regional serologic surveys to determine the extent of severe acute respiratory syndrome coronavirus 2 (SARS-CoV-2) in the population and these results will permit the estimation of Canada's infection fatality rate (14).

Estimating excess mortality will increase our understanding of the impact of the COVID-19 pandemic beyond the disease itself. For example, an increase in deaths due to other causes may be expected as a result of individuals whose fear of infection prevents them from seeking timely health care. Excess mortality is the difference between the total number of people who died from any cause during a specified period, and the historical average for the same time of year in previous years. In June 2020, Statistics Canada released a provisional dataset on excess deaths for January to the week of May 2, 2020, as compared with the previous five years (15). These data were preliminary and, as more information becomes available for all Canadian jurisdictions, we will gain a better understanding of the true impact of the pandemic on Canadians.

\section{Authors' statement}

DP - Conceptualization, original draft, review and editing $\mathrm{CB}$ - Conceptualization, data curation, formal analysis, review and editing

JM - Data curation, formal analysis, review and editing

LW - Review and editing

AC - Conceptualization, review and editing

CA - Review and editing

LS - Review and editing

DT - Review and editing

DM - Review and editing

JP - Review and editing

\section{Competing interests}

None.

\section{Acknowledgements}

Authors wish to thank provincial and territorial surveillance partners, the National Microbiology Laboratory, provincial public health laboratory partners, and the Health Portfolio Operations Centre's Surveillance Team, Public Health Agency of Canada.

Public Health Agency of Canada COVID-19 Surveillance and Epidemiology Team included D Paquette, C Bell, J Macri, L Whitmore, A Currie, C Archibald, L Shah, D Taylor, D MacDonald and J Pennock.

\section{Funding}

This work was supported by Public Health Agency of Canada.

\section{References}

1. Our World in Data. Statistics and Research. Coronavirus (COVID-19) Deaths (accessed 2020-07-24). https://ourworldindata.org/covid-deaths

2. Zhou F, Yu T, Du R, Fan G, Liu Y, Liu Z, Xiang J, Wang Y, Song B, Gu X, Guan L, Wei Y, Li H, Wu X, Xu J, Tu S, Zhang Y, Chen $\mathrm{H}$, Cao B. Clinical course and risk factors for mortality of adult inpatients with COVID-19 in Wuhan, China: a retrospective cohort study [published correction appears in Lancet. 2020 Mar 28;395(10229):1038]. Lancet 2020 Mar;395(10229):1054-62. DOI PubMed 
3. Chen $T$, Wu D, Chen $H$, Yan W, Yang D, Chen G, Ma K, Xu D, Yu H, Wang H, Wang T, Guo W, Chen J, Ding C, Zhang X, Huang J, Han M, Li S, Luo X, Zhao J, Ning Q. Clinical characteristics of 113 deceased patients with coronavirus disease 2019: retrospective study. BMJ 2020 Mar;368:m1091. DOI PubMed

4. Verity R, Okell LC, Dorigatti I, Winskill P, Whittaker C, Imai N, Cuomo-Dannenburg G, Thompson H, Walker PG, Fu H, Dighe A, Griffin JT, Baguelin M, Bhatia S, Boonyasiri A, Cori A, Cucunubá Z, FitzJohn R, Gaythorpe K, Green W, Hamlet A, Hinsley W, Laydon D, Nedjati-Gilani G, Riley S, van Elsland S, Volz E, Wang H, Wang Y, Xi X, Donnelly CA, Ghani AC, Ferguson NM. Estimates of the severity of coronavirus disease 2019: a model-based analysis. Lancet Infect Dis 2020 Jun;20(6):669-77. DOI PubMed

5. World Health Organization. Medical certification, ICD mortality coding, and reporting mortality associated with COVID-19. COVID-19: Surveillance, case investigation and epidemiological protocols. WHO; June 72020 (accessed 2020-07-05). https://www.who.int/publications/i/item/WHO2019-nCoV-mortality-reporting-2020-1

6. International Long Term Care Policy Network. Hsu AT, Lane N, Sinha SK, Dunning J, Dhuper M, Kahiel Z, Sveistrup $\mathrm{H}$. Understanding the impact of COVID-19 on residents of Canada's long-term care homes - ongoing challenges and policy responses (updated 2020-0604). https://ltccovid.org/wp-content/uploads/2020/06/ LTCcovid-country-reports_Canada_June-4-2020.pdf

7. Jordan RE, Adab P, Cheng KK. Covid-19: risk factors for severe disease and death. BMJ 2020 Mar;368:m1198. DOI PubMed

8. Livingston E, Bucher K. Coronavirus Disease 2019 (COVID-19) in Italy. JAMA 2020 Apr;323(14):1335. DOI PubMed
9. Gardner W, States D, Bagley N. The Coronavirus and the Risks to the Elderly in Long-Term Care. J Aging Soc Policy 2020 Jul-Oct;32(4-5):310-5. DOI PubMed

10. Pan D, Sze $S$, Minhas JS, Bangash MN, Pareek N, Divall $P$, Williams CM, Oggioni MR, Squire IB, Nellums LB, Hanif W, Khunti K, Pareek M. The impact of ethnicity on clinical outcomes in COVID-19: A systematic review. EClinicalMedicine 2020 Jun;23:100404. DOI PubMed

11. Ontario Agency for Health Protection and Promotion (Public Health Ontario). Enhanced Epidemiological Summary. COVID-19 in Ontario - A focus on diversity: January 15, 2020 to May 14, 2020.-Toronto (ON): Queen's Printer for Ontario; 2020. https://www.publichealthontario.ca/-/ media/documents/ncov/epi/2020/06/covid-19-epi-diversity. pdf?la=en

12. CBC News. Rocha R, Shingler B, Montpetit J. Montreal's poorest and most racially diverse neighborhoods hit hardest by COVID-19, data analysis shows. June 11, 2020. https://www.clbc.ca/news/canada/montreal/race-covid19-montreal-data-census-1.5607123

13. Government of Canada. Interim guidance: Care of residents in long term care homes during the COVID-19 pandemic. Government of Canada; updated July 17, 2020 (accessed 2020-07-24). https://www.canada.ca/en/ public-health/services/diseases/2019-novel-coronavirusinfection/guidance-documents/residents-long-term-car e-homes-covid-19.html

14. COVID-19 Immunity Task Force. About (accessed 2020-0705). https://www.covid19immunitytaskforce.ca/about/

15. Statistics Canada. Provisional death counts and excess mortality, January to April 2019 and January to April 2020. Ottawa (ON): StatCan; June 19, 2020 (accessed 2020-07-05). https://www150.statcan.gc.ca/n1/daily-quotidien/200513/ dq200513d-eng.htm 